Article

\title{
Designing Sustainable Public Transportation: Integrated Optimization of Bus Speed and Holding Time in a Connected Vehicle Environment
}

\author{
Wei Wu ${ }^{1}$, Wanjing Ma ${ }^{2}$, Kejun Long ${ }^{1}$, Heping Zhou ${ }^{1}$ and Yi Zhang ${ }^{3,4, *}$ \\ 1 School of Traffic and Transportation Engineering, Changsha University of Science and Technology, \\ Changsha 410004, China; jiaotongweiwu@csust.edu.cn (W.W.); klong29@utk.edu (K.L.); \\ 002788@csust.edu.cn (H.Z.) \\ 2 Key Laboratory of Road and Traffic Engineering of the Ministry of Education, TongjiUniversity, \\ Shanghai 201804, China; mawanjing@tongji.edu.cn \\ 3 State Key Laboratory of Ocean Engineering, Shanghai Jiao Tong University, Shanghai 200240, China \\ 4 Key Laboratory of Special Environment Road Engineering of Hunan Province, \\ Changsha University of Science \& Technology, Changsha 410004, China \\ * Correspondence: darrenzhy@sjtu.edu.cn; Tel.: +86-21-3420-6334
}

Academic Editor: Bhavik Bakshi

Received: 1 August 2016; Accepted: 7 November 2016; Published: 12 November 2016

\begin{abstract}
Developing public transportation and giving priority to buses is a feasible solution for improving the level of public transportation service, which facilitates congestion alleviation and prevention, and contributes to urban development and city sustainability. This paper presents a novel bus operation control strategy including both holding control and speed control to improve the level of service of transit systems within a connected vehicle environment. Most previous work focuses on optimization of signal timing to decrease the bus signal delay by assuming that holding control is not applied; the speed of buses is given as a constant input and the acceleration and deceleration processes of buses can be neglected. This paper explores the benefits of a bus operation control strategy to minimize the total cost, which includes bus signal delay, bus holding delay, bus travel delay, acceleration cost due to frequent stops and intense driving. A set of formulations are developed to explicitly capture the interaction between bus holding control and speed control. Experimental analysisand simulation tests have shown that the proposed integrated operational model outperforms the traditional control, speed control only, or holding control only strategies in terms of reducing the total cost of buses. The sensitivity analysis has further demonstrated the potential effectiveness of the proposed approach to be applied in a real-time bus operation control system under different levels of traffic demand, bus stop locations, and speed limits.
\end{abstract}

Keywords: bus operation control; speed adjustment; holding control; advanced public transit systems

\section{Introduction}

In 2013, urban Americans experienced an extra 6.8 billion hours of travel and 3.1 billion gallons of fuel consumed because of traffic congestion [1]. An additional 500 million hours and 700 million gallons of fuel were consumed in 2013 than in 2009 [1,2]. As these trends continue, travel delays will grow to 8.2 billion hours and wasted fuel will increase to 3.7 billion gallons in 2020 [1]. Congestion alleviation and prevention have become urgent tasks for urban development and city sustainability $[3,4]$. To deal with traffic congestion, researchers proposed plenty of methods to improve road capacity, including road network planning [5,6], roadway design [7], traffic signal control [8,9], and so on [10,11]. Those methods documented their advantages to reduce traffic congestion and played significant roles in improving road network efficiency. However, the growth rate of road capacity can never meet the 
requirements of traffic demands. According to the statistics and predictions, the world had a population of 1.2 billion vehicles in 2014, and that will grow to 2.0 billion in 2035 [12]. Therefore, an increasing number of traffic engineers have realized that developing public transportation and giving priority to buses is a feasible solution to reduce congestion [13-17].

In order to give priority to buses, a commonly employed method is holding a vehicle at a bus stop [18-20]. A schedule-based approach holds a bus for some additional time to improve the regularity [21-24], while a headway-based approach tries to reduce the variability of headways downstream of this holding control stop [25-27]. Most of the previous studies are trying to use holding control to improve bus dispatching. However, when a bus stop is located upstream of a signalized intersection, holding a bus for a period of time could be treated as a strategy to avoid a second stop at the end of the queue formed during the red light [28]. The elimination of stops results in reducing fuel consumption and vehicle emissions and enhances the comfort for passengers, thus improving the level of bus service. However, holding buses at bus stations causes some additional waiting time to passengers, and passengers value their waiting time almost twice of what it actually is [29]. Therefore, the maximum bus holding time cannot be set too long.

Transit signal priority (TSP) is another promising option to give priority to buses. With TSP, buses can request the green phase of traffic signals to claim the right-of-way and proceed unimpeded through an intersection [30]. Many studies have proposed TSP strategies and documented the benefits of TSP implementations [31-38]. However, most existing methods for transit signal priority are proposed assuming that the TSP system has no holding control, and that the speed of buses are given as constant $[31,39]$. However, in reality, firstly, holding control can determine bus dwell time at bus stops significantly, thus causing deviations of the bus arrival time at the stop line. Even small deviation of bus arrival time may result in low TSP efficiency, or even TSP system failure. Secondly, real-time bus speed is a function of several factors, including bus driver behavior, bus characteristics, impacts of upstream signals, and traffic conditions even with an exclusive bus lane [40]. Moreover, most existing references concerning TSP focus on optimize signal timing to reduce congestions, but fuel consumptions and pollution emissions are also important sustainable parameters to evaluate the benefits of TSP.

The implementation of holding control and speed control relies on effective, accurate, two-way communication between buses and the intersection controller. The emersion of connected vehicle (CV) technology is an excellent solution to this problem. On the basis of dedicated short range communications (DSRC), CV technology ensures real-time communication between buses and the intersection controller [41-43]. Buses send information of running status, including speed, acceleration, position, estimated arrival time, requesting phase, etc. to the controller, while obtaining messages, like green light start time, duration of the green light, and so on, from the controller. The basic scenario is illustrated in Figure 1.

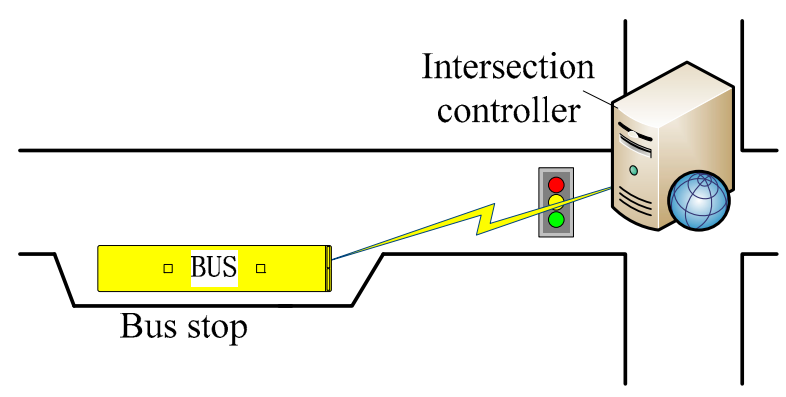

Figure 1. Basic scenario for bus operation control within a connected vehicle environment.

To summarize the above concerns, this research focuses on developing a bus operational strategy including both holding control and speed control to reduce bus delays, fuel consumption, and pollution emissions within a connected vehicle environment. The primary contribution of this paper is to: 
- Explicitly capture the dynamic interaction between bus acceleration, speed, and holding time;

- Optimize bus speed and holding time of buses dynamically in an united framework;

- Satisfy the objectives of both improving driving patterns of buses and minimizing the bus delay, fuel consumption, and pollution emissions, which is conducive for city sustainability.

\section{Development of the Optimization Model}

\subsection{Problem Description}

The basic idea of the proposed model is illustrated in Figure 2. Trajectory 1 is the normal trajectory for buses. After boarding and alighting the passengers, the bus closed the door and is ready to depart from the bus stop at time $T_{c}$. Then the bus will accelerate to $V_{a}$, joining the queue formed by the red light. Trajectory 2 stands for the bus operation strategy with speed control. In this case, the bus also departs from the bus stop immediately at $T_{c}$, but it will accelerate to a relatively lower speed $V_{l}$; then it can clear the intersection without stopping again. Trajectory 3 represents the bus operation strategy with holding control. By holding the bus $t_{h}$ seconds at the bus stop, then the bus can also clear the intersection without another stop.

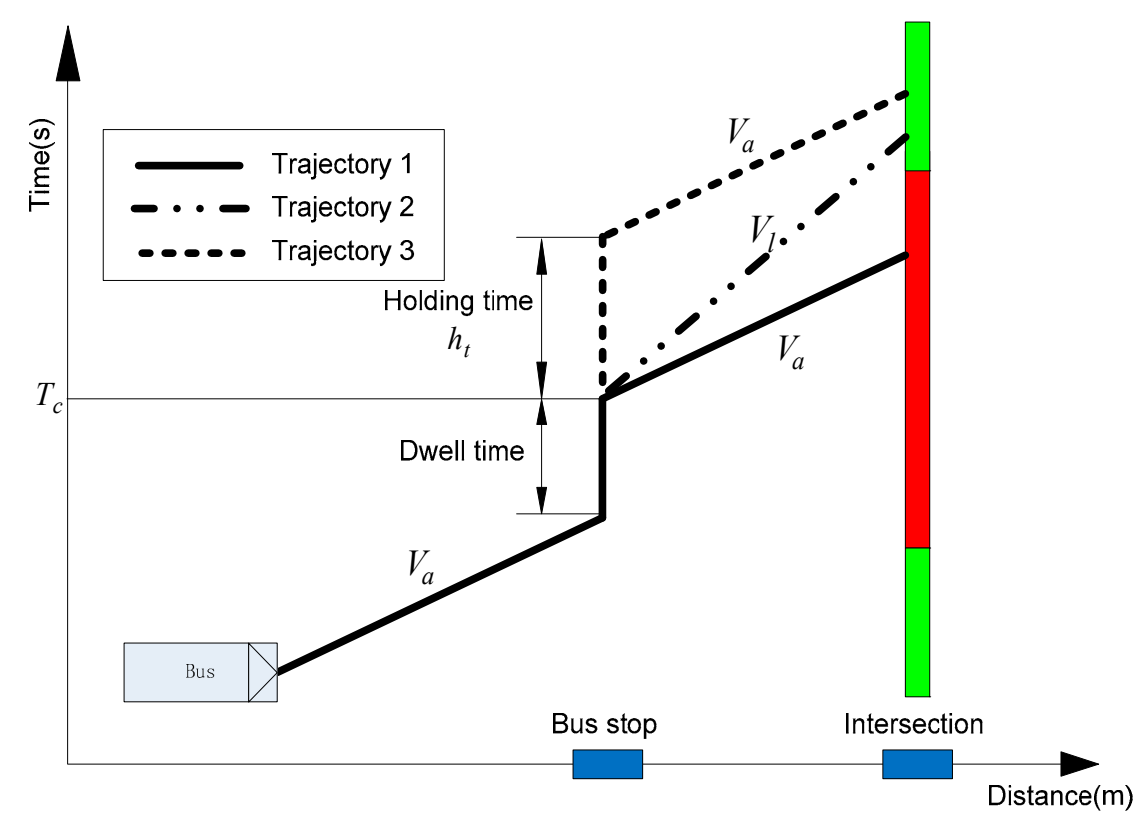

Figure 2. Space-time diagram of three different bus operations.

\subsection{General Notations}

The main notations used hereafter are summarized in Table 1.

Table 1. List of key variables used in the formulations.

\begin{tabular}{cc}
\hline Key Variables & Definition \\
\hline$a_{\min }, a_{\max }$ & The maximum and minimum accelerations forbuses $\left(\mathrm{m} / \mathrm{s}^{2}\right)$ \\
$C_{0}$ & Cycle length of the signal timing $(\mathrm{s})$ \\
$D_{b u s}$ & Bus delay cost $(\mathrm{s})$ \\
$d_{h}$ & Bus holding delay $(\mathrm{s})$ \\
$d_{s}$ & Bus signal delay $(\mathrm{s})$ \\
$d_{t}$ & Bus travel delay $(\mathrm{s})$ \\
$L$ & The distance from bus stop to the intersection $(\mathrm{m})$ \\
\hline
\end{tabular}


Table 1. Cont.

\begin{tabular}{cc}
\hline Key Variables & Definition \\
\hline$L_{q}$ & The maximum queue length $(\mathrm{m})$ \\
$l_{v}$ & The average vehicle length $(\mathrm{m})$ \\
$q$ & Arrival flow rate (\# of vehs $/ \mathrm{s})$ \\
$s$ & Saturation flow rate (\# of vehs $/ \mathrm{s})$ \\
$T_{c}$ & Time for buses ready to depart from bus stop (s) \\
$T_{g}$ & Time for green light starts (s) \\
$T_{j}$ & Time for buses join in the queue (s) \\
$T_{q}$ & Time for queue dissipated (s) \\
$T_{t}$ & Time for buses clearing the intersection (s) \\
$T_{A B}, T_{B C}, T_{C D}, T_{D A}$ & The boundary point for scenario $A, B, C$ and $D(\mathrm{~s})$ \\
$t_{h}$ & Time duration for holding the bus at bus stop (s) \\
$t_{0 \_v}$ & Time duration for a bus accelerates from zero to bus traveling speed (s) \\
$V_{b u s}$ & Bus traveling speed (m/s) \\
$V_{\min }, V_{\max }$ & The maximum and minimum bus speed limits (m/s) \\
\hline
\end{tabular}

\subsection{Objective Function}

The objective function in this research is to minimize the total cost of the buses, including delay cost, stop cost, and acceleration cost. It can be denoted as:

$$
\min \left(d_{b u s}+\alpha f_{b u s}+\beta p_{b u s}\right)
$$

where $d_{b u s}$ denotes bus delays, $f_{b u s}$ is the number of stops of buses, $p_{b u s}$ is the acceleration or deceleration cost of buses, and $\alpha$ and $\beta$ are weighting factors. In this objective function, $d_{b u s}$ is the delay cost referring to traffic congestion, and $f_{b u s}$ and $p_{b u s}$ are the acceleration cost referring to fuel consumptions and pollution emissions.

In this study, both holding control and speed control are considered. Therefore, bus delays consist of three parts: bus travel delay $d_{t}$, bus holding delay $d_{h}$, and bus signal delay $d_{s}$. Then bus delays can be computed as:

$$
d_{b u s}=d_{t}+d_{h}+d_{s}
$$

where $d_{t}$ is caused by the actual travelling speed of buses smaller than design speed, $d_{h}$ is caused by holding buses with some extra time at bus stops, and $d_{s}$ is caused by the red light.

With respect to $p_{b u s}$ and $f_{b u s}$, the smaller value the $p_{b u s}$ or $f_{b u s}$ is, the lower fuel consumption and pollution emissions will be. The deceleration cost $p_{b u s}$ can be computed with real-time bus acceleration, which is specified as:

$$
p_{\text {bus }}=\int_{T_{\mathcal{c}}}^{T_{t}}\left|a_{t}\right|
$$

where $a_{t}$ is the real-time acceleration or deceleration of buses, and $T_{c}$ is the start time for beginning the optimization scheme. In this study, $T_{\mathcal{C}}$ is the time point of buses closing the door at the bus stop and ready to depart, and $T_{t}$ is the time for buses clearing the intersection after optimization. The number of stops of buses $f_{\text {bus }}$ can be computed according to real-time bus travelling speed and acceleration, which is specified as:

$$
\begin{gathered}
f_{\text {bus }}^{t}=\left\{\begin{array}{cc}
1 & V_{\text {bus }}^{t}=0 \text { and } \lim _{x \rightarrow t^{-}} a_{x}<0 \\
0 & \text { other cases }
\end{array}\right. \\
f_{\text {bus }}=\int_{T_{c}}^{T_{t}} f_{\text {bus }}^{t}
\end{gathered}
$$

where $V_{b u s}^{t}$ is the bus travelling speed at time $t$. Equation (4) ensures there is only one stop of the bus being counted, when the bus stopped from $0 \mathrm{~s}$ to $10 \mathrm{~s}$, because of the red light, for example. 


\subsection{Decision Variables}

The decision variables of the integrated optimization model can be defined as follows:

(1) Holding time at bus stop, $t_{h}$.

(2) Bus traveling speed, $V_{b u s}$.

\subsection{Constraints}

The optimization of the proposed model starts with the bus closing the door and preparing to leave the bus stop at time $T_{c}$. As illustrated in Figure 3, the cycle time $C_{0}$ can be divided into four scenarios according to $T_{c}$. In scenario $A$, even when both holding control and speed control are employed, buses will still be stopped by the red light. In scenario $B$, if both holding control and speed control are implemented, buses are able to clear the intersection without stopping. In scenario $C$, buses can proceed through the intersection unimpeded by adjusting its travel speed. In scenario $D$, buses can clear the intersection smoothly without any optimization. In some cases, either holding control or speed control can guarantee buses clearing the intersection without stopping. In this situation, speed control will be preferred in this study because passengers will be impatient if holding control is employed.

- $\quad$ Scenario $A$, when $0<T_{\mathcal{C}}<T_{A B}$ or $T_{D A}<T_{c}<C_{0}$ (including $A_{1}$ and $A_{2}$ );

- Scenario $B$, when $T_{A B} \leq T_{C}<T_{B C}$;

- Scenario $C$, when $T_{B C} \leq T_{C}<T_{C D}$;

- Scenario $D$, when $T_{C D} \leq T_{C}<T_{D A}$.

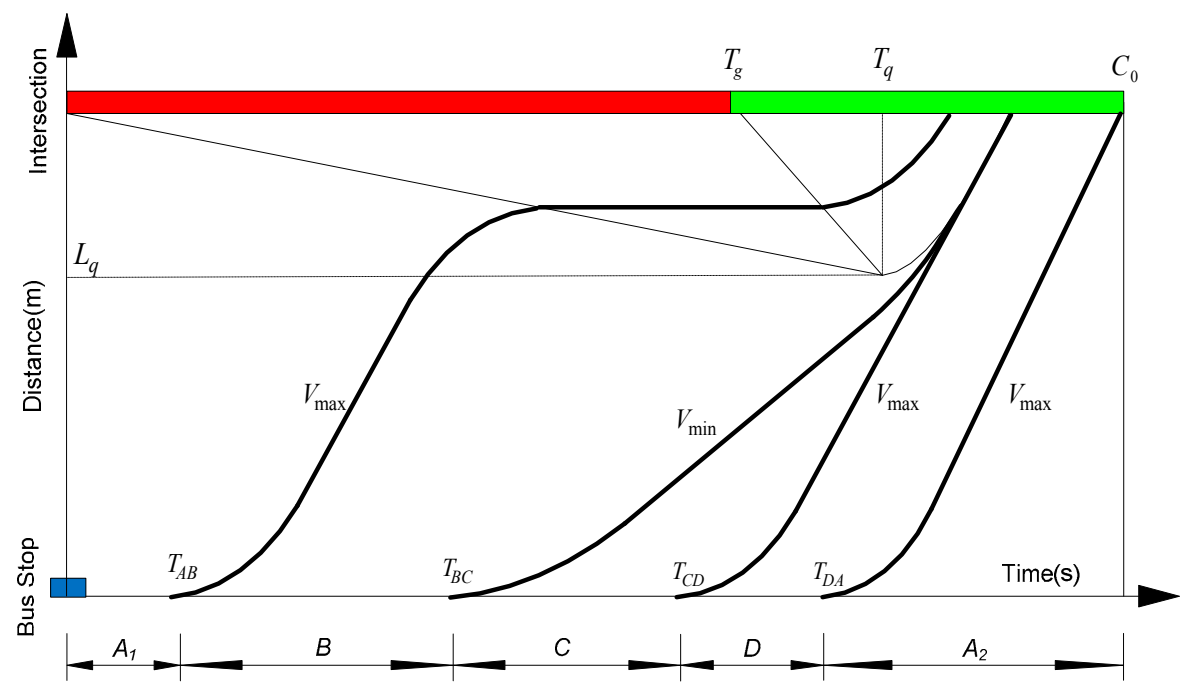

Figure 3. Scenarios for the buses departing from the bus stop.

In the following analysis, the calculation method for the objective function given by Equation (1) will be specified based on different scenarios.

\subsubsection{Scenario A}

In this scenario, buses will be stopped by the red light no matter if speeding up or holding control is employed. Since the queue length caused by red light grows continuously, the bus should depart from the bus stop immediately and then accelerate to $V_{b u s}$ to obtain a good place in the queue. Thus, in this situation, the holding time for the bus is equal to zero. Then the holding delay $d_{h}$ can be specified as:

$$
d_{h}=0
$$


The time duration for the bus accelerating from zero to $V_{b u s}$ can be computed as:

$$
t_{0 \_v}=V_{b u s} / a_{b u s}
$$

The boundary of $V_{b u s}$ and $a_{b u s}$ can be specified as:

$$
\begin{gathered}
V_{\min } \leq V_{b u s} \leq V_{\max } \\
a_{\min } \leq a_{b u s} \leq a_{\max }
\end{gathered}
$$

The time that the bus joins the queue can be computed as:

If $0<T_{\mathcal{C}}<T_{A B}$, then:

$$
T_{j}=\frac{T_{c} V_{b u s}+L+V_{b u s} t_{0 \_v}}{V_{b u s}+q l_{v}}
$$

If $T_{D A}<T_{\mathcal{C}}<C_{0}$, then:

$$
T_{j}=\frac{T_{c} V_{b u s}+L+V_{b u s} t_{0 \_v}-C_{0} V_{b u s}}{V_{b u s}+q l_{v}}
$$

The time that the bus starts to move can be computed as:

$$
T_{s}=T_{g}+q T_{j} / s
$$

Then the signal delay caused by the red light $d_{S}$ can be computed as:

$$
d_{s}=T_{s}-T_{j}
$$

With respect to bus travel delay $d_{t}$, it is caused by travelling with a lower speed, which can be computed as:

$$
d_{t}=\frac{L}{V_{a}}-\frac{L}{V_{\max }}
$$

where $V_{a}$ is the average bus travel speed.

\subsubsection{Scenario B}

In scenario $B$, buses could clear the intersection without stopping if both holding control and speed control are applied. By holding the bus at the bus stop after time passes the boundary point $T_{B C}$, then the bus status scenario will move from $B$ to $C$ (the detailed analysis of the speed control in scenario $C$ will be discussed later). Thus, in scenario $B$, the bus will be held at the bus stop. If the holding time of the bus at the bus stop is too long, passengers will complain and be impatient. Therefore, the lower and upper bound of the holding time should be set as:

$$
0 \leq d_{t} \leq d_{t_{-} \max }
$$

where $d_{t}$ max is the maximum holding time that is allowed. Then, the time of the boundary point $T_{A B}$ and $T_{B C}$ can be computed as:

$$
\begin{gathered}
T_{A B}=\frac{T_{g} s}{s-q}-\left(L-\frac{T_{g} s q l_{v}}{s-q}\right) / V_{\min }-t_{h \_\max } \\
T_{B C}=\frac{T_{g} s}{s-q}-\left(L-\frac{T_{g} s q l_{v}}{s-q}\right) / V_{\min }
\end{gathered}
$$


In scenario $B$, the bus holding delay can be specified as:

$$
d_{h}=d_{t}
$$

The other part of the cost in scenario $B$ will be the same with which in the scenario $C$.

\subsubsection{Scenario C}

In scenario $C$, buses can depart from bus stop immediately, and then accelerate to a relatively smaller speed $V_{l}$ by speed control to reach the tail of the queue. Finally, the bus will accelerate and follow the last vehicle in the queue to travel through the intersection. In this case, the time for queue dissipation follows that:

$$
T_{q}=\frac{s T_{g}}{s-q}
$$

The maximum queue length can be computed as:

$$
L_{q}=\frac{s T_{g} q l_{v}}{s-q}
$$

Then the bus travelling speed can be specified as:

$$
V_{l}=\frac{L-q l_{v} T_{q}}{T_{q}-0.5 t_{0 \_}-T_{c}}
$$

The bus travelling delay can be specified as:

$$
d_{t}=0.5 t_{0 \_v}+\left(L-L_{q}\right) / V_{l}+L_{q} / V_{a}-L / V_{\max }
$$

In this scenario, holding control is not applied, and buses can clear the intersection without signal delay, which can be specified as:

$$
\begin{aligned}
& d_{h}=0 \\
& d_{s}=0
\end{aligned}
$$

\subsubsection{Scenario D}

Scenario $D$ is the simplest situation for buses. Buses can always clear the intersection unimpeded without any optimization. Either holding control or speed control is not necessary in this scenario. The boundary point $T_{C D}$ and $T_{D A}$ can be specified as:

$$
\begin{aligned}
& T_{C D}=T_{q}-\left(L-L_{q}\right) / V_{\max } \\
& T_{D A}=C_{0}-\frac{L}{V_{\max }}-\frac{V_{\max }}{2 a_{\max }}
\end{aligned}
$$

There is only a travelling delay for buses in this scenario, and it can be computed as:

$$
d_{t}=\frac{V_{b u s}}{2 a_{b u s}}+\frac{L}{V_{b u s}}-\frac{L}{V_{\max }}
$$

With regard to $p_{b u s}$ and $f_{b u s}$ in each scenario, the computational methods are illustrated in Equations (3)-(5).

In summary, the mathematical description of the integrated model is recapitulated as follows:

$$
\begin{gathered}
\operatorname{Min}\left(d_{b u s}+\alpha f_{b u s}+\beta p_{b u s}\right) \\
\text { s.t. Equation (2) - Equation (27) }
\end{gathered}
$$




\subsubsection{Optimization of the Proposed Method}

The minimization is a nonlinear programming problem, which is programmed in Microsoft Visual Studio C++ (Redmond, WA, USA) to solve it in our study. The C++ optimization flow chart of the proposed method, including the four scenarios and the aforementioned formula, is shown in Figure 4 . Note that in scenario $B$, the bus delay is computed in the same way as for scenario $C$.

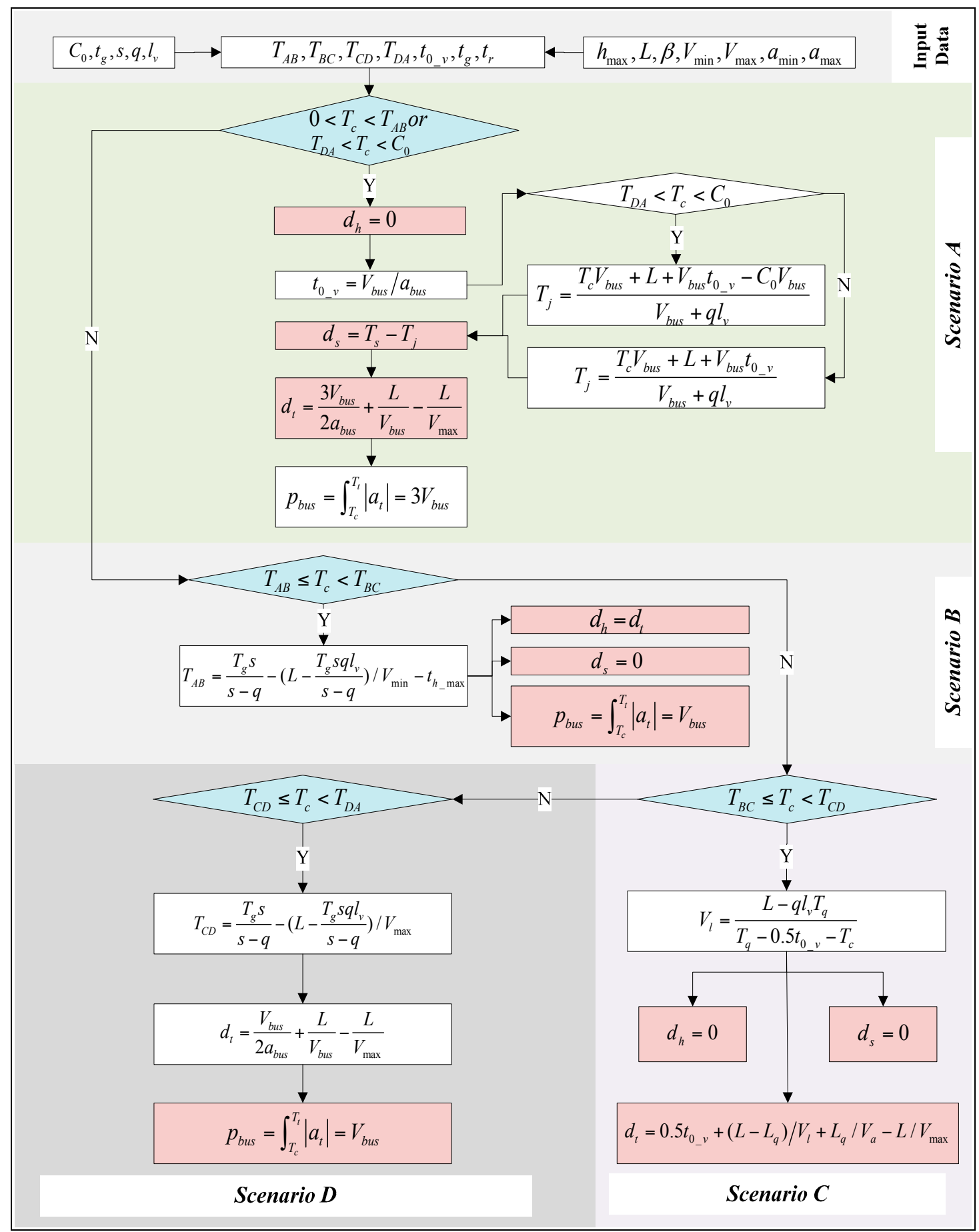

Figure 4. Optimization flowchart for the proposed method.

The optimization flowchart could be illustrated by five steps: 
- Step 1: Given the cycle time, traffic demands, and the location of the bus stop, compute the green time duration, the maximum green extension time, and the time boundary points for each scenario.

- Step 2: If the bus arrival time is not located in scenario $A$, then turn to step 3. Otherwise, compute the time point at which the bus stopped by the red light and the time point at which the bus started to move by the green light. Then compute the bus signal delay caused by the red light, the queue, and the bus acceleration cost.

- Step 3: If the bus arrival time is not located in scenario $B$, then turn to step 4. Otherwise, compute the bus holding time and bus travel speed, then compute the bus holding delay, travel delay, and the bus acceleration cost.

- Step 4: If the bus arrival time is not located in scenario $C$, then turn to step 5. Otherwise, compute the optimal bus travel speed, and then compute the bus travel delay and the bus acceleration cost.

- Step 5: Compute the bus travelling delay and bus acceleration cost in scenario $D$.

\section{Results and Discussion}

\subsection{Performance Analysis}

To evaluate the performance of the proposed model, The following parameters are assumed: $C_{0}=70 \mathrm{~s}, t_{g}=35 \mathrm{~s}, s=0.5 \mathrm{veh} / \mathrm{s}, q=0.15 \mathrm{veh} / \mathrm{s}, l_{v}=6 \mathrm{~m}, h_{\max }=15 \mathrm{~s}, L=200 \mathrm{~m}, \alpha=1, \beta=1$, $V_{\min }=5.6 \mathrm{~m} / \mathrm{s}(20 \mathrm{~km} / \mathrm{h}), V_{\max }=11.1 \mathrm{~m} / \mathrm{s}(40 \mathrm{~km} / \mathrm{h}), a_{\min }=-3 \mathrm{~m} / \mathrm{s}, a_{\max }=3 \mathrm{~m} / \mathrm{s}$. The values assigned to $a_{\min }$ and $a_{\max }$ are relatively smaller than those in a real situation because passengers will have an uncomfortable ride experience if the acceleration or deceleration is too intense.

By employing the above parameters, the boundary point for each scenario can be computed as $T_{A B}=7.3 \mathrm{~s}, T_{B C}=22.3 \mathrm{~s}, T_{C D}=36.0, T_{D A}=50.1 \mathrm{~s}$. The performance of the proposed method will be compared with the following different methods:

- Case 1: Traditional control method with neither holding nor speed control;

- Case 2: Speed control only;

- Case 3: Holding control only;

- Case 4: The proposed control method including both holding and speed control.

In this study, in order to explore the worst condition of the proposed model, it is assumed that buses will always travel at maximum speed. In this situation, speed control can only cause extra delays and is not able to decrease delays. Table 2 shows the optimization and comparison results of different cases, which clearly reveal that the performance of different cases in scenario $A$ and $D$ would be the same. In detail, in scenario $A$, buses will depart immediately to get a good place in the queue, then be stopped by the red light in all of the cases. In scenario $D$, buses will also depart immediately from the bus stop and then proceed at maximum speed to clear the intersection without stopping. In scenario $B$, the average bus delay cost of the proposed method is higher. This is because, in this scenario, only the result coming from the proposed method needs to perform a holding control. Holding control can cause extra delays because the queue grows due to the red light, but it can optimize the bus's driving cycle. This has been verified in Table 2, in which the average acceleration cost in scenario $B$ of the proposed model is much smaller than other cases. The total cost (the sum of the average bus delay cost plus average acceleration cost) of the proposed method in scenario $B$ is the smallest. In scenario $C$, buses will perform speed control in cases 2 and 4 . In case 3 , holding control will be applied. Comparing case 3 to cases 2 and 4, the results stay the same. This illustrates that the performance of speed control can be identical with the holding control. Comparing case 1 with other cases, the results clearly show that either speed control or holding control can cause extra bus delay costs in this study, but it can be compensated by reducing the average acceleration cost. 
Table 2. Comparisons of results at different cases.

\begin{tabular}{ccccc}
\hline $\begin{array}{c}\text { Scenario } \\
\boldsymbol{T}_{\boldsymbol{c}}\end{array}$ & \multicolumn{4}{c}{$\begin{array}{c}\text { Average Bus Delay Cost } \\
\text { (Average Acceleration Cost) }\end{array}$} \\
\cline { 2 - 5 } & Case 1 & Case 2 & Case 3 & Case 4 \\
\hline Scenario $A$ & 30.5 & 30.5 & 30.5 & 30.5 \\
$T_{\mathcal{c}} \in(-24.9,7.3)$ & $(33.3)$ & $(33.3)$ & $(33.3)$ & $(33.3)$ \\
\hline Scenario $B$ & 16.9 & 18.7 & 16.9 & 26.1 \\
$T_{\mathcal{C}} \in[7.3,22.3)$ & $(33.3)$ & $(31.3)$ & $(33.3)$ & $(11.1)$ \\
\hline Scenario $C$ & 8.8 & 10.2 & 10.2 & 10.2 \\
$T_{\mathcal{c}} \in[22.3,36.0)$ & $(33.3)$ & $(11.1)$ & $(11.1)$ & $(11.1)$ \\
\hline Scenario $D$ & 1.85 & 1.85 & 1.85 & 1.85 \\
$T_{\mathcal{c}} \in[36.0,50.1]$ & $(11.1)$ & $(11.1)$ & $(11.1)$ & $(11.1)$ \\
\hline & & & &
\end{tabular}

Let $t_{w}$ denotes the time interval in which buses can clear the intersection without stopping in one signal timing cycle, $t_{l}$ denotes the interval length of $t_{w}$, and $t_{s}$ is the service rate for bus in the whole cycle. Then:

$$
t_{s}=t_{l} / C_{0}
$$

Table 3 presents the results of bus service rate in different cases. The results clearly show that the proposed method (case 4) can provide buses with a $61.1 \%$ service rate, which outperforms all other cases.

Table 3. Results of the bus service rate for different cases.

\begin{tabular}{cccc}
\hline Cases & $\boldsymbol{t}_{\boldsymbol{w}}$ & $\boldsymbol{t}_{\boldsymbol{l}}$ & $\boldsymbol{t}_{\boldsymbol{s}}$ \\
\hline Case 1 & {$[36.0,50.1]$} & 14.1 & $20.1 \%$ \\
Case 2 & {$[21.0,50.1]$} & 29.1 & $41.6 \%$ \\
Case 3 & {$[22.3,50.1]$} & 27.8 & $39.7 \%$ \\
Case 4 & {$[7.3,50.1]$} & 42.8 & $61.1 \%$ \\
\hline
\end{tabular}

\subsection{SimulationTest}

To further verify the performance of the proposed model in a more realistic scenario, a simulation test by PTV VISSIM 5.3 (Karlsruhe, Germany) is employed. VISSIM is a worldwide traffic and transportation simulator, which can simulate the stochastic nature and detailed interactions of traffic flows. In the simulation, bus frequency was set to $30 \mathrm{veh} / \mathrm{h}$, the other parameters are kept the same with the above statement. The VISSIM COM interface is employed to implement speed control and holding control. Every parameter combination is simulated 20 times under different random seeds. The simulation lasts $4200 \mathrm{~s}$ each time. Performance data will be collected from $900 \mathrm{~s}$ to $4200 \mathrm{~s}$, while $0 \mathrm{~s}$ to $900 \mathrm{~s}$ will be used to warm up the simulation. After the simulation test, the performance data, including bus delay, fuel consumption, and pollution emissions, are collected. The results are illustrated in Figure 5.

As in Figure 5, by employing holding control in cases 3 and case 4, and applying speed control in cases 2 and case 4, bus delay increases while fuel consumption and pollution emissions decrease, compared with case 1 . More specifically, after optimization of the proposed model, bus delay increases $2.4 \%$ to $9.4 \%$, while fuel consumption decreases $8.9 \%$ to $19.6 \%$, and pollution emissions decrease $3.5 \%$ to $13.1 \%$. 


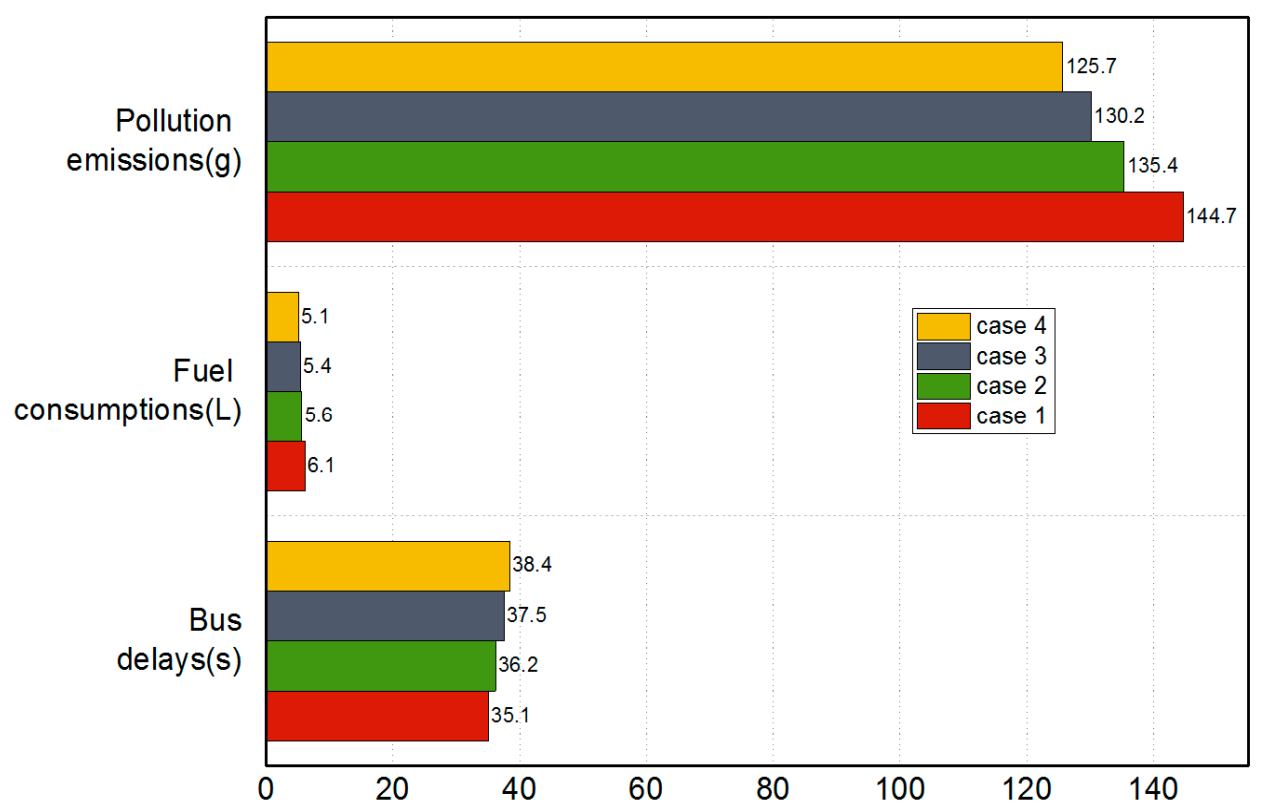

Figure 5. Simulation results for different cases.

\subsection{Sensitivity Analysis}

To investigate the performance of the proposed model under different situations, three sets of sensitivity analysis of the parameters, including the degree of saturation (volume-to-capacity ratio), bus stop location, and maximum speed limit, are employed in the following sections.

\subsubsection{Sensitivity Analysis with Degree of Saturation}

In this paper, the degree of saturation $s_{d}$ (volume-to-capacity ratio) can be specified as:

$$
s_{d}=q C_{0} / s t_{g}
$$

Figure 6 displays the performance results in the different cases under different degrees of saturation. The total cost is computed by Equation (1).

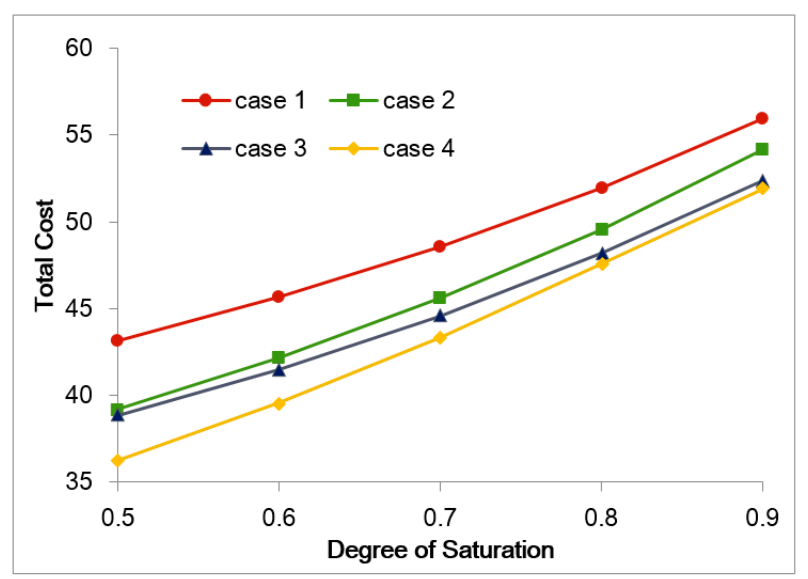

Figure 6. Comparison of total cost under different degrees of saturation.

The graphical results clearly indicate that the total cost of buses increases with the degree of saturation in all cases. Case 4 (proposed method) always has the smallest total cost and outperforms all of the other three cases even when the degree saturation reaches 0.9 . 


\subsubsection{Sensitivity Analysis with Bus Stop Location}

Bus stop location (distance between bus stop and traffic light) could impact the effectiveness of speed control. Figure 7 displays the performance results in the different cases under different bus stop locations.

In Figure 7, with the increase of the distance between bus stop and traffic light, the total cost in cases 2 and 4 decreases. With regard to case 1 and case 3 , the total cost would stay the same. The results illustrate that the change of bus stop location could only affect the effectiveness of the speed control. Since case 1 and case 3 have no speed control, the total cost will always stay the same. Another finding is that the proposed method (case 4) will always have the smallest total cost.

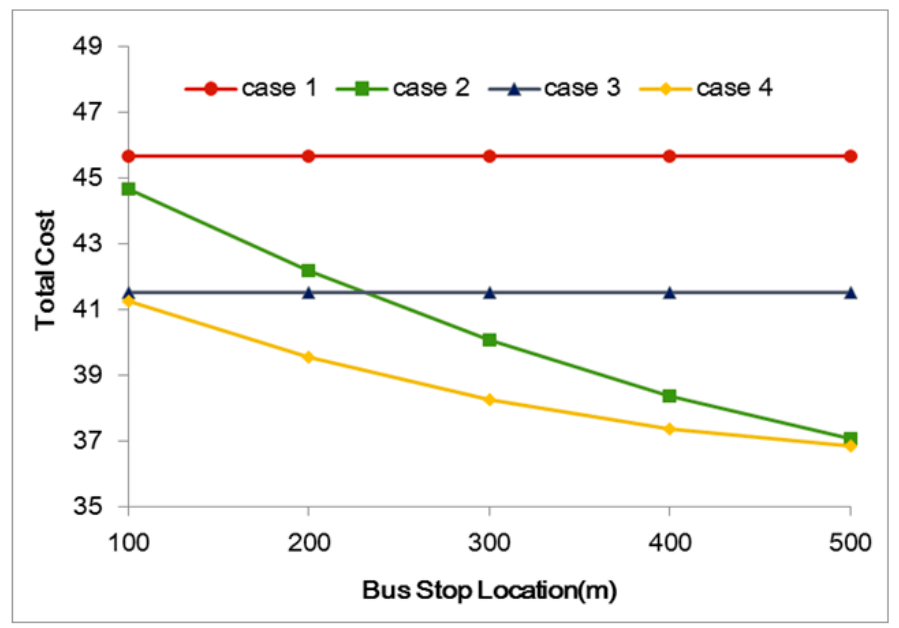

Figure 7. Comparison of total cost under different bus stop locations.

\subsubsection{Sensitivity Analysis with Maximum Speed Limits}

Figure 8 displays the performance results in different cases under different maximum speed limits.

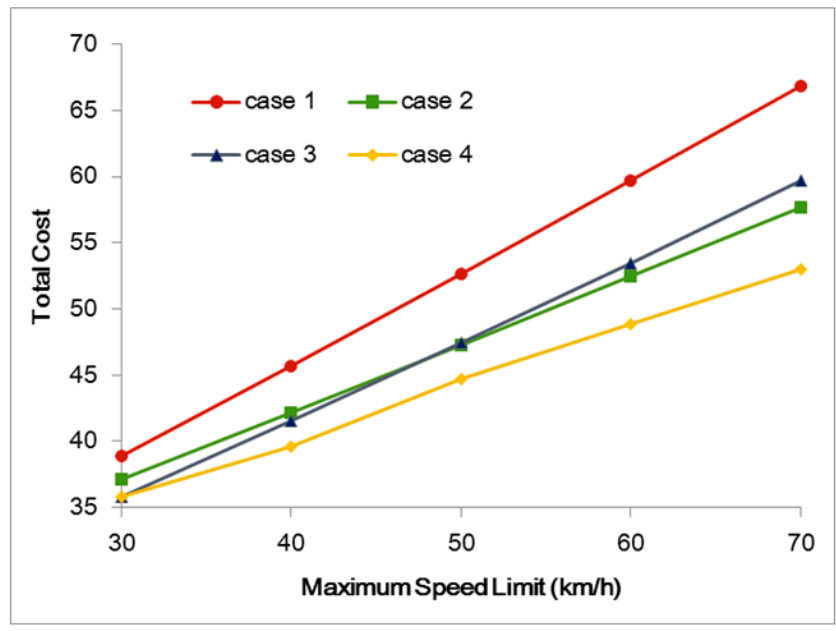

Figure 8. Comparison of total cost under different maximum speed limits.

As illustrated in Figure 8, the total cost increases with the maximum speed limit. This is because the travel delay of buses $d_{t}$ can be specified as:

$$
d_{t}=\frac{L}{V_{b u s}}-\frac{L}{V_{\max }}
$$


Since $V_{\max }$ increases, the travel delay will increase. However, with the increase of the maximum bus speed, the bus could proceed with a higher speed, which can expand the bus service rate mentioned in Equation (28). Additionally, the proposed method (case 4) will outperform all other cases with the smallest cost.

\section{Strengths and Limitations}

This studyhas a number of strengths and limitations. In terms of the strengths, this study focuses on decreasing bus cost and the number of stops to improve the level of service of transit systems. This would facilitate sustainable motorization and urbanization because public transportation helps to reduce energy consumption and vehicle emissions. Secondly, the study revealed the effects of bus holding control and speed control on bus delays while most previous studies merely focus on the optimization of signal timing. Finally, the study investigated the benefits of holding control and speed control bycomparing with different control measures. In terms of the limitations, the proposed model was restricted to a single intersection, and a large scale analysis and modeling will be conducted in future studies. Moreover, the study employs numerical tests to investigate the benefits of the proposed model, and more realistic or field tests are required to apply the proposed model in a practical project.

\section{Conclusions}

This paper presents a novel approach for integrated optimization of bus holding time at a bus stop, the acceleration of the bus, and bus speed to improve the level of service of a transit system. The objective of the proposed model is to minimize the total cost, which includes bus signal delay, bus holding delay, bus travel delay, and acceleration cost due to frequent stops and intense driving. A set of formulations are developed to explicitly capture the interaction between bus holding control and speed control. Experimental analyses and simulation tests have shown that the proposed integrated operational model outperforms the traditional control, speed control only, and holding control only strategies in terms of reducing the total cost of buses. The sensitivity analysis has further demonstrated the potential of the proposed approach to be applied in a real-time bus operation control system under different traffic demands, bus stop locations, and speed limits. Note that this study has presented a preliminary theoretical analysis and evaluation results for the proposed model. More extensive numerical experiments or field tests will be conducted to assess the effectiveness of the proposed model under various traffic and transit demand patterns. Another possible extension of this study is to optimize signal timings, holding time duration, and recommended bus speed, together to further improve the level of service of buses.

Acknowledgments: The research has been supported by the National Natural Science Foundation of China under Grant No. 51408065 and No. 51308336, the key project of the National Natural Science Foundation of China under Grant No.51338002, the Science and Technology Project of the Ministry of Transport under Grant No.2014319825190, the Research Foundation of Education Bureau of Hunan Province under Grant No. 14B003, the Natural Science Foundation of Hunan Province under Grant No. 2015JJ6001, the Fundamental Research Funds for the Central Universities (Shanghai Jiao Tong University) under Grant No. 16JXYB08, the Open Fund of the Key Laboratory of Special Environment Road Engineering of Hunan Province (Changsha University of Science \& Technology) under Grant No. KFJ150503, and the Project "Key Technology of Urban Transportation System in Big Cities" of Shanghai Municipal Engineering Design Institute (Group) Co., Ltd. (SMEDI).

Author Contributions: In this paper, Wei Wu developed the research ideas and designed the research programs, participated in the development of optimization model, analyzed the results and completed the writing of the Introduction, Results and Discussion. Wanjing Ma committed to the choice of proper modeling methods and the writing of the corresponding parts. Kejun Long carried out the optimization of the proposed model and completed the writing work of the corresponding parts. Heping Zhou carried out the sensitivity analysis of the proposed model and completed the writing work of the corresponding parts. Yi Zhang carried out the evaluation and analysis of the proposed model and completed the writing work of the corresponding parts.

Conflicts of Interest: The authors declare no conflict of interest. 


\section{References}

1. Schrank, D.; Eisele, B.; Lomax, T. 2014 Urban Mobility Report: Powered by INRIX Traffic Data; Southwest Region University Transportation Center: College Station, TX, USA, 2015.

2. Zhang, W.; Lu, J.; Xu, P.; Zhang, Y. Moving towards Sustainability: Road Grades and On-Road Emissions of Heavy-Duty Vehicles-A Case Study. Sustainability 2015, 7, 12644-12671. [CrossRef]

3. Verma, A.; Rahul, T.M.; Dixit, M. Sustainability impact assessment of transportation policies-A case study for Bangalore city. Case Stud. Trans. Policy 2015, 3, 321-330. [CrossRef]

4. Zhang, Y.; Li, Y.; Yang, X.; Liu, Q.; Li, C. Built Environment and Household Electric Bike Ownership: Insights from Zhongshan Metropolitan Area, China. Trans. Res. Rec. J. Trans. Res. Board 2013, 2387, 102-111. [CrossRef]

5. Szeto, W.Y.; Jiang, Y.; Wang, D.Z.W.; Sumalee, A. A Sustainable Road Network Design Problem with Land Use Transportation Interaction over Time. Netw. Spat. Econ. 2013, 15, 1-32. [CrossRef]

6. Hosseininasab, S.M.; Shetab-Boushehri, S.N. Integration of selecting and scheduling urban road construction projects as a time-dependent discrete network design problem. Eur. J. Oper. Res. 2015, 246, 762-771. [CrossRef]

7. Zhao, J.; Ma, W.; Head, K.L.; Yang, X. Dynamic Turning Restriction Management for Multiple Signalized Intersections: A Lane-based Approach. In Proceedings of the Transportation Research Board 94th Annual Meeting, Washington, DC, USA, 11-15 January 2015.

8. Han, K.; Liu, H.; Gayah, V.V.; Friesz, T.L.; Yao, T. A robust optimization approach for dynamic traffic signal control with emission considerations. Trans. Res. Part C Emerg. Technol. 2016, 7, 3-26. [CrossRef]

9. Cui, C.Y.; Shin, J.S.; Miyazaki, M.; Lee, H.H. Real-time traffic signal control for optimization of traffic jam probability. IEEJ Trans. Electron. Inf. Syst. 2013, 96, 1-13. [CrossRef]

10. Zhang, Y.; Wu, W.; Li, Y.; Liu, Q.; Li, C. Does the Built Environment Make a Difference? An Investigation of Household Vehicle Use in Zhongshan Metropolitan Area, China. Sustainability 2014, 6, 4910-4930. [CrossRef]

11. Zhang, Y.; Li, Y.; Liu, Q.; Li, C. The Built Environment and Walking Activity of the Elderly: An Empirical Analysis in the Zhongshan Metropolitan Area, China. Sustainability 2014, 6, 1076-1092. [CrossRef]

12. Moorhead, J.; Nixon, T. Carbon Pricing on the Horizon; Thomson Reuters: New York, NY, USA, 2015.

13. Almasi, M.H.; Sadollah, A.; Kang, S.; Karim, M.R. Optimization of an Improved Intermodal Transit Model Equipped with Feeder Bus and Railway Systems Using Metaheuristics Approaches. Sustainability 2016, 8, 537. [CrossRef]

14. Nuzzolo, A.; Comi, A. Advanced Public Transport and ITS: New modelling challenges. Trans. Trans. Sci. 2016, 12, 674-699.

15. Bigerna, S.; Polinori, P. Willingness to Pay and Public Acceptance for Hydrogen Buses: A Case Study of Perugia. Sustainability 2015, 7, 13270-13289. [CrossRef]

16. He, H.; Guler, S.I.; Menendez, M. Adaptive control algorithm to provide bus priority with a pre-signal. Trans. Res. Part C Emerg. Technol. 2016, 64, 28-44. [CrossRef]

17. Moreira-Matias, L.; Mendes-Moreira, J.; De Sousa, J.F.; Gama, J. Improving Mass Transit Operations by Using AVL-Based Systems: A Survey. IEEE Trans. Intell. Trans. Syst. 2015, 16, 1636-1653. [CrossRef]

18. Hickman, M.D. An analytic stochastic model for the transit vehicle holding problem. Trans. Sci. 2001, 35, 215-237. [CrossRef]

19. Eberlein, X.J.; Wilson, N.H.M.; Bernstein, D. The Holding Problem with Real-Time Information Available. Trans. Sci. 2001, 35, 1-18. [CrossRef]

20. Zhao, J.; Bukkapatnam, S.; Dessouky, M.M. Distributed architecture for real-time coordination of bus holding in transit networks. IEEE Trans. Intell. Trans. Syst. 2003, 4, 43-51. [CrossRef]

21. Xuan, Y.; Daganzo, C.F.; Cassidy, M.J. Increasing the capacity of signalized intersections with separate left turn phases. Trans. Res. Part B Methodol. 2011, 45, 769-791. [CrossRef]

22. Zhao, J.; Dessouky, M.; Bukkapatnam, S. Optimal slack time for schedule-based transit operations. Trans. Sci. 2006, 40, 529-539. [CrossRef]

23. Sun, A.; Mark, H. Scheduling considerations for a branching transit route. J. Adv. Trans. 2010, 38, $243-290$. [CrossRef]

24. Steinzen, I.; Gintner, V.; Suhl, L.; Kliewer, N. A Time-Space Network Approach for the Integrated Vehicle-and Crew-Scheduling Problem with Multiple Depots. Trans. Sci. 2010, 44, 367-382. [CrossRef] 
25. Daganzo, C.F. A headway-based approach to eliminate bus bunching: Systematic analysis and comparisons. Trans. Res. Part B Methodol. 2009, 43, 913-921. [CrossRef]

26. Dell'Olio, L.; Ibeas, A.; Ruisánchez, F. Optimizing bus-size and headway in transit networks. Transportation 2012, 39, 449-464. [CrossRef]

27. Zolfaghari, S.; Azizi, N.; Jaber, M.Y. A model for holding strategy in public transit systems with real-time information. Int. J. Trans. Manag. 2004, 2, 99-110. [CrossRef]

28. Koehler, L.A.; Kraus, W. Simultaneous control of traffic lights and bus departure for priority operation. Trans. Res. Part C Emerg. Technol. 2010, 18, 288-298. [CrossRef]

29. Wu, J.; Liu, M.; Sun, H.; Li, T.; Gao, Z.; Wang, D.Z. Equity-based timetable synchronization optimization in urban subway network. Trans. Res. Part C Emerg. Technol. 2015, 51, 1-18. [CrossRef]

30. Ma, W.; Liu, Y.; Yang, X. A dynamic programming approach for optimal signal priority control upon multiple high-frequency bus requests. J. Intell. Trans. Syst. 2013, 17, 282-293. [CrossRef]

31. Abdy, Z.R.; Hellinga, B.R. Analytical method for estimating the impact of transit signal priority on vehicle delay. J. Trans. Eng. 2011, 137, 589-600. [CrossRef]

32. Xu, H.; Sun, J.; Zheng, M. Comparative analysis of unconditional and conditional priority for use at isolated signalized intersections. J. Trans. Eng. 2010, 136, 1092-1103. [CrossRef]

33. Ma, W.; Yang, X.; Liu, Y. A dynamic programming model for optimal bus signal priority control with multiple requests. In Proceedings of the 90th Transportation Research Board Annual Meeting, Washington, DC, USA, 23-27 January 2011.

34. Liu, Y.; Chang, G.L.; Yu, J. An integrated control model for freeway corridor under nonrecurrent congestion. IEEE Trans. Veh. Technol. 2011, 60, 1404-1418. [CrossRef]

35. Smith, H.R.; Hemily, B.; Ivanovic, M. Transit Signal Priority (TSP): A Planning and Implementation Handbook. In Proceedings of the Ite Annual Meeting \& Exhibit, Melbourne, Australia, 7-10 August 2015.

36. Baker, R.J.; Collura, J.; Dale, J.J.; Head, L.; Hemily, B.; Ivanovic, M.; Jarzab, J.T.; Mccormick, D.; Obenberger, J.; Smith, L. An Overview of Transit Signal Priority. Available online: https://trid.trb.org/view.aspx?id=723986 (accessed on 27 October 2016).

37. Dion, F.; Rakha, H. Evaluation of Potential Transit Signal Priority Benefits along a Fixed-Time Signalized Arterial. J. Trans. Eng. 2004, 130, 294-303. [CrossRef]

38. Rakha, H.; Zhang, Y. Sensitivity Analysis of Transit Signal Priority Impacts on Operation of a Signalized Intersection. J. Trans. Eng. 2004, 130, 796-804. [CrossRef]

39. Ghanim, M.; Dion, F.; Abu-Lebdeh, G. Integration of Signal Control and Transit Signal Priority Optimization in Coordinated Network Using Genetic Algorithms and Artificial Neural Networks. In Proceedings of the Transportation Research Board 88th Annual Meeting, Washington, DC, USA, 11-15 January 2009.

40. Ma, W.; Liu, Y.; Han, B. A rule-based model for integrated operation of bus priority signal timings and traveling speed. J. Adv. Trans. 2013, 47, 369-383. [CrossRef]

41. Abu-Lebdeh, G. Exploring the Potential Benefits of IntelliDrive-Enabled Dynamic Speed Control in Signalized Networks. In Proceedings of the 89th Annual Meeting of the Transportation Research Board, Washington, DC, USA, 10-14 January2010.

42. Wu, W.; Li, P.K.; Zhang, Y. Modelling and simulation of vehicle speed guidance in connected vehicle environment. Int. J. Simul. Model. 2015, 14, 145-157. [CrossRef]

43. Ding, J.; He, Q.; Head, L.; Saleem, F.; Wu, W. Development and Testing of Priority Control System in Connected Vehicle Environment. In Proceedings of the 92th Annual Meeting of the Transportation Research Board, Washington, DC, USA, 13-17 January2013.

(C) 2016 by the authors; licensee MDPI, Basel, Switzerland. This article is an open access article distributed under the terms and conditions of the Creative Commons Attribution (CC-BY) license (http://creativecommons.org/licenses/by/4.0/). 